\title{
Rede de Pesquisadores de Créditos de Carbono no Brasil entre 2006 e 2012: Um Estudo Bibliométrico e Sociométrico ${ }^{1}$
}

\section{Network of Researchers of Carbon Credits in Brazil between 2006 and 2012: A Bibliometric and Sociometric Study}

\section{Red de Investigadores de Créditos de Carbono en Brasil entre 2006 y 2012: un Bibliométrico Estudio y Sociométrico}

\author{
Antonio Nunes Pereira, Me. \\ Instituto Federal do Ceará - Reitoria, IFCE - Campus Iguatu. \\ Rodovia Iguatu-Várzea Alegre, Zona Rural, CEP: 63.500-000 - \\ Iguatu, CE - Brasil, Telefone: (88) 3582-1000 \\ e-mail: anp2308@gmail.com \\ Ana Cristina de Faria, Dr. ${ }^{\text {a }}$ \\ Universidade Nove de Julho, Mestrado Profissional em \\ Gestão Ambiental e Sustentabilidade. \\ Av. Francisco Matarazzo, 612, Água Branca, CEP: 05.001-100, \\ São Paulo, SP, Brasil, Telefone: (11) 3665-9313 \\ e-mail: e-mail: anacfaria@uol.com.br
}

\author{
Ademir Lamenza, Dr. \\ Universidade de São Caetano do Sul - USCS \\ Universidade Nove de Julho, Curso de Ciências Gerenciais. \\ Rua Tagipuru, 812, Barra Funda, CEP: 01.156-000, São Paulo, \\ SP - Brasil, Telefone: (11) 3823-9066 \\ e-mail: adm.lamenza@uscs.edu.br \\ Raquel Silva Pereira, Dr. \\ Universidade Municipal de São Caetano do Sul, Programa de \\ Pós-Graduação e Pesquisa em Administração \\ Rua Santo Antônio, 50, Centro, CEP: 09.521-160, São Caetano \\ do Sul, SP - Brasil, Telefone: (11) 42393354 \\ e-mail: raquelspereira@uol.com.br
}

\section{RESUMO}

O presente estudo contribui com o mapeamento da produção científica sobre o tema Créditos de Carbono, delimitado aos eventos e periódicos selecionados a partir do ranking da Qualis/CAPES na área de Administração, Contabilidade e Turismo (ACT), entre 2006 e 2012; bem como a periódicos que estão no repositório do Scielo. Este estudo pode ser considerado empírico-analítico, no que diz respeito a sua abordagem metodológica. No que tange aos procedimentos técnicos empregados, pode-se caracterizar a investigação como pesquisa documental, bibliométrica e sociométrica, com ênfase nos artigos produzidos sobre Créditos de Carbono. Foi possível identificar que a produção científica sobre Créditos de Carbono está concentrada no evento EnANPAD e no periódico RGSA. Tal fato sinaliza que o crescimento da publicação em eventos não acompanhou a veiculação em revistas, evidenciando um campo majoritariamente incipiente junto à comunidade acadêmica analisada. A análise de redes sociais possibilitou a identificação de quatro redes mais produtivas ligadas institucionalmente à Universidade Federal do Rio de Janeiro, à Universidade Federal da Bahia, à Universidade de São Caetano do Sul e à Universidade de São Paulo, que não possuem vínculos de autoria entre essas.

Palavras-chave: Créditos de Carbono. Bibliometria. Sociometria.

\footnotetext{
${ }^{1}$ Artigo recebido em 02.06.2013. Revisado pelos pares em 30.09.2013 (blind review). Ajustado e Aceito para publicação em 01.09.2014. Recomendado para publicação por José Ribamar Marques de Carvalho (Editor Científico). Publicado em 15.12.2014. Organização responsável UACC/CCJS/UFCG.
} 


\section{ABSTRACT}

This study aims to mapping scientific literature on the topic carbon credit delimited to events and periodicals selected from the ranking of Qualis/CAPES in the area of administration, accounting and tourism-ACT between 2006 and 2012; as well as journals that are in the repository. This study can be considered empirical analytical, as regards its methodological approach. With respect to technical procedures, employees can be characterized the investigation as bibliographical research, Bibliometric, and sociometric, with emphasis in articles produced on carbon credits. It was possible to identify the scientific production on carbon credit is concentrated in the Stock and in the periodical RGSA. This signals that the publication's growth did not follow the events serving in magazines, highlighting a field largely incipient along to the academic community. The social network analysis has enabled the identification of three networks more productive linked institutionally to the Federal universities of Rio de Janeiro and Bahia, of University of São Caetano do Sul, and the University of São Paulo and that do not have links by each other.

Keywords: Carbon credits. Bibliometrics. Sociometry.

\section{RESUMEN}

Este estudio contribuye a la asignación de la literatura científica sobre los Créditos de Carbono tema, limitada a los eventos y publicaciones seleccionadas del ranking de Qualis / CAPES en Administración, Contabilidad y Turismo (ACT) entre 2006 y 2012; y las revistas que están en repositorio Scielo. Este estudio puede ser considerado empírico-analítico, en cuanto a su enfoque metodológico. Con respecto a los procedimientos técnicos utilizados, se puede caracterizar a la investigación como la investigación documental, bibliométrico y sociométrico, con hincapié en los artículos producidos en los créditos de carbono. Fue posible identificar la literatura científica sobre los créditos de carbono se concentra en caso EnANPAD y revista RGSA. Este hecho indica que el crecimiento de la publicación en eventos no siguió la colocación en las revistas, mostrando un campo emergente en su mayoría en la comunidad académica analizado. Análisis de redes sociales permitió la identificación de cuatro redes más productivos conectados institucionalmente la Universidad Federal de Río de Janeiro, la Universidad Federal de Bahía, de la Universidad de São Caetano do Sul y la Universidad de Sao Paulo, que la falta de vínculos entre autoría estos.

Palabras clave: Créditos de Carbono. Bibliometría. Sociometry.

\section{INTRODUÇÃO}

Um problema que as lideranças internacionais terão que resolver, porque se insere como o conjunto de questões ambientais a serem enfrentadas e cujo ônus será creditado às próximas gerações, é o que Marcovitch (2006) descreve como a crise ambiental universal do futuro. Este autor enfatiza que as questões ambientais fazem-se sentir porque a Organização Metereológica Mundial aferiu que a última década, entre o final do Século XX e início do Século XXI, foi o mais quente da história. O Século XX foi o mais quente do milênio e,nos próximos cem anos, o planeta pode ter a temperatura aumentada em até 3,5 graus centígrados.

De acordo com essa perspectiva, e não havendo medidas preventivas suficientes contra o aquecimento, observa-se a tendência de aumento do aquecimento na superfície terrestre e nos oceanos. Uma das causas é a emissão de dióxido de carbono $\left(\mathrm{CO}_{2}\right)$ na atmosfera, provocando mudanças climáticas (OPCC, 2001). Essa visão está descrita em 
pormenores na publicação do $4^{\underline{0}}$ Relatório do IPCC - Painel Intergovernamental sobre Mudanças Climáticas, de 2007, sobre as considerações e previsões para o aquecimento global.

Diante dos grandes acontecimentos no meio ambiente, a Organização das Nações Unidas (ONU) tem debatido há mais de uma década sobre os Gases de Efeito Estufa (GEE), que causam o aquecimento global. Como resultados dessas reuniões, foram firmados acordos entre os países participantes, dentre os quais, destaca-se o Protocolo de Kyoto de 1997, que regulamenta a defesa global do clima. Na visão de Maciel et al. (2009), o conceito de "sequestro de carbono", debatido na conferência de Kyoto, visa a frear o efeito estufa reduzindo o dióxido de carbono da atmosfera.

Os desequilíbrios ambientais impactaram as decisões das nações em relação à degradação ambiental, sendo que muito deve ser feito para a contenção da poluição, envolvendo o maior número de nações, embasadas nas propostas do Protocolo de Kyoto. Nessa perspectiva, empresas e países promovem um rápido uso dos projetos de Mecanismos de Desenvolvimento Limpo - MDL, os quais serão tratados, posteriormente, neste trabalho (PEREZ et al., 2008).

O Protocolo de Kyoto caracteriza as possibilidades de negociações em um novo mercado, o de Créditos de Carbono, em que se mostra intensa a procura por parte dos países signatários do referido protocolo para esse tipo de comercialização, devido às metas para o seu cumprimento. Essas metas obrigam os países integrantes a reduzir emissões de poluentes por meio de desenvolvimento de tecnologias limpas no país de origem ou financiamento do desenvolvimento de MDL em países em desenvolvimento. Tais metas passaram a vigorar a partir de 2008 e foram limitadas ao ano de 2012, de acordo com a Conferência das Partes - COP 17, realizada na África do Sul, no final de 2011.

Diante dessa contextualização e da relevância do tema, o problema que norteia esta pesquisa é: Quais características bibliométricas podem ser obtidas da produção científica sobre Créditos de Carbono no Brasil? Para responder a esta questão, este trabalho propõe-se a mapear a produção científica brasileira entre 2006 e 2012, bem como a identificar quais são as redes de pesquisadores existentes no país e como instituições mais produtivas têm atuado no referido tema.

A estrutura do artigo, para cumprir seus objetivos, segue uma lógica dedutivoempírica. Na primeira fase é apresentada a revisão de literatura nacional e internacional sobre Créditos de Carbono e redes organizacionais. Num segundo momento, com apoio dos métodos sociométricos de análise de vínculos de autoria, é realizada uma imersão empírica para investigar o campo de estudo, contemplando: autores mais produtivos, seus vínculos e suas respectivas universidades. Por fim, o estudo estabelece um diálogo entre os resultados da investigação bibliométrica e o fenômeno de redes de buracos estruturais.

\section{FUNDAMENTAÇÃO TEÓRICA}

Neste tópico, será tratado sobre conceitos básicos de Sustentabilidade e Crédito de Carbono.

\subsection{Sustentabilidade: Conceitos e Gestão}

O conceito de Desenvolvimento Sustentável surgiu a partir do conceito de eco desenvolvimento proposto na $1^{a}$. Conferência das Nações Unidas sobre o Meio Ambiente e 
Desenvolvimento, na Suécia, em 1972, e que se tornou um paradigma que preconizava degradação ambiental, confusão sobre o papel do crescimento econômico e os conceitos de sustentabilidade e participação dos envolvidos (LELÉ, 1991). Em linha com o movimento de desenvolvimento proposto pela referida Conferência, Miller Jr. (2008) afirma que, para viver de forma sustentável, deve-se atrelar/interagir com o meio ambiente, a ecologia, a ciência ambiental, o ambientalismo e a sustentabilidade. Cabe, então, revisar o conceito de sustentabilidade e seus derivados, elemento conceitual da presente investigação.

O desenvolvimento sustentável teve maior significância social no documento Nosso Futuro Comum, publicado pela Comissão Mundial sobre Meio Ambiente e Desenvolvimento, conhecido como Relatório Bruntland (WCED). Este relatório define o conceito de Desenvolvimento Sustentável como: “o desenvolvimento que satisfaz as necessidades de geração presente sem comprometer a capacidade de as gerações futuras satisfazerem as suas próprias necessidades" (WCED, 1987, p.46).

Preocupação externada por Miller Jr. (2008) está vinculada à relação entre população e recursos naturais renováveis e não renováveis. Os processos de industrialização e urbanização já caracterizavam elevada densidade demográfica. Em 1950 o mundo tinha 2,5 bilhões de habitantes e em 2005 contava com 6,5 bilhões de habitantes, com crescimento médio de $1,2 \%$ ao ano, caracterizando uma relação desproporcional entre ambiente construído e ambiente natural: alterações nos sistemas de energia, a diversidade biológica nativa com alterações significativas por meio da retirada de florestas e o desbalanceamento dos principais ciclos, como o ciclo da água e seus cursos e a impermeabilização do solo.

Sachs (1993) propôs dimensões da sustentabilidade, de forma que atendam a todas as possibilidades como: a) sustentabilidade social; b) sustentabilidade economica; c) sustentabilidade ecológica; d) sustentabilidade espacial e e) sustentabilidade cultural. $\mathrm{Na}$ visão de Pereira (2002), o desenvolvimento deixou de ser sinônimo de crescimento ou melhoria quantitativa, passando a representar, também mudanças qualitativas, do nível micro para o macro, ou seja, com ênfase do regional para o planeta.

O desenvolvimento sustentável, conforme Moraes (2009) existe desde que o homem convive com a natureza e, portanto, deve preservá-la para a continuidade na obtenção de alimentos e vestiário. A sabedoria e tradição indígena demonstram às populações urbanas os beneficios em conservar-se a natureza. Para o autor, a Teoria de Malthus foi a primeira teoria populacional que relacionou o crescimento da população com a fome, afirmando a tendência do crescimento populacional em progressão geométrica e do crescimento da oferta de alimentos em progressão aritmética.

Cabe, então, incluir uma perspectiva teórica que diferencia a sustentabilidade de conceitos correlatos e, não raro, intercambiáveis de forma errônea. Uma visão relevante seria então segregar "o que não é" do "que efetivamente é" a sustentabilidade, bem como amarrar as perspectivas anteriores. Das perspectivas apresentadas, pode-se destacar um aspecto que parece essencial no conceito de sustentabilidade: a atuação presente para a preservação dos interesses das gerações futuras. Essa proposta feita pelo WCDE permanece como conceito central das políticas empresariais e públicas, para a atuação sustentável dos agentes econômicos. Há, nesse contexto, diferenciadas formas de atuar, sendo a utilização de Créditos de Carbono, uma opção que se almeja como mais adequada e oportuna. 


\subsection{Crédito de Carbono: Um Avanço do Mecanismo de Desenvolvimento Limpo (MDL)}

A partir das possibilidades oriundas do emprego das ferramentas de Redução de Emissões Certificadas (RCEs), das empresas que buscam a sustentabilidade, tal situação pode possibilitar diversos ganhos às organizações e aos profissionais em questão. Especificamente, nessas organizações, tal situação pode evidenciar novas possibilidades, até então, nunca experimentadas, principalmente, em função do dinamismo intrínseco ao negócio dessas organizações.

Conforme Seiffert (2009), com o predomínio de uma crescente tendência das dimensões do mercado de RCE, a comercialização de Créditos de Carbono pode gerar oportunidades de negócios para o Brasil, devido ao potencial do país que, nos últimos anos, ocupa posição de destaque em projetos sustentáveis, dentre os quais abordam vários setores da economia. Assim, sumariamente, tem-se: Energias renováveis; Substituição de combustíveis fósseis; Sequestro de carbono/Reflorestamento; Manejo de resíduos animais e Indústrias Químicas e Indústrias de Base.

Na visão de Seiffert (2009), as perspectivas de aumento dos índices de poluição para os próximos anos desencadearão compromissos que demonstrem um envolvimento por parte dos países signatários do Protocolo de Kyoto, devido às metas de cumprimento das legislações desse, que obrigam os países integrantes a reduzirem emissões de poluentes, por meio de desenvolvimento de tecnologias limpas no país de origem, ou financiamento do desenvolvimento de MDL em países emergentes. Essas metas prevêem um plano de redução das emissões de gases poluentes, que provocam o "efeito estufa".

As metas definidas pelo Protocolo de Kyoto exigem uma resposta efetiva dos países desenvolvidos para a questão da diminuição da poluição mundial e o apoio aos países em desenvolvimento em projetos de redução das emissões de Gases do Efeito Estufa(GEEs), em que o Brasil e outros países em desenvolvimento, que podem negociar seus projetos próprios de redução de poluentes com países, ainda, não conseguiram alcançar a meta de redução estabelecida no Protocolo de Kyoto (SEGRETI; BITO, 2006).

De acordo com Maciel et al (2009), os países em desenvolvimento são mais vulneráveis à mudança climática, pois possuem menos recursos para responder à variação natural do clima. Apesar dessa peculiaridade, Governos e empresas pertencentes aos países em desenvolvimento encontraram na redução da emissão dos gases causadores do efeito estufa, uma alternativa para combater a poluição e expandir as suas receitas por meio da comercialização de Créditos de Carbono, em que os executores do projeto, por meio de corretores ambientais especializados, vendem créditos antes de serem efetivamente gerados.

Conforme o relatório do Painel Intergovernamental sobre Mudanças Climáticas IPCC de 2007, a preocupação com o controle das emissões de poluentes torna-se a cada dia mais presente em discussões mundiais e comerciais em diversos níveis das organizações e áreas de atuação das indústrias, serviços e consumo. Isso se deve ao reflexo das crescentes mudanças climáticas do Planeta que proporcionaram uma nova visão sobre como manter um desenvolvimento de forma sustentável.

Yamin (2006) apresenta que a maior ênfase sobre o assunto ocorreu a partir do ECO 92, realizada no Rio de Janeiro, na qual o principal objetivo era conciliar desenvolvimento econômico com a conservação e proteção dos ecossistemas da Terra, e durante a UNFCCC United Nations Framework Convention on Climate Change. Trata-se de uma instituição, por assim dizer, que coordena todas as ações de crédito de carbono. Naquela época, os processos de regulamentações ambientais que tramitavam não possuíam um envolvimento mundial, 
ocorriam muitas ações isoladas e as perspectivas não eram animadoras em virtude disso. Assim, as convenções da UNFCCC empenharam-se para desenvolver um sistema que tivesse argumentos e propostas tangíveis a nível mundial.

$\mathrm{Na}$ convenção internacional Rio+20, em 2012, pouco se abordou sobre o tema. Tal situação pode ser explicada, parcialmente, pela expectativa de uma reunião específica para o tema, a COP. Nessa perspectiva, pode-se defender que não houve ambiente adequado para se tratar do Protocolo de Kyoto na Cúpula Rio+20, ensejando um novo encontro para o tema.

O Protocolo de Kyoto estabelece metas diferentes a cada país integrante, divididas conforme a contribuição de cada um com as emissões de GEEs lançadas desde a época da Revolução Industrial. Os Estados Unidos não ratificaram o Protocolo de Kyoto, embora seja o país com índices elevados de poluição do planeta que participa em torno de $25 \%$ do total da poluição (PEREZ et al., 2008).

O motivo alegado para a não ratificação norte-americana seria o momento de recessão e instabilidade econômica. Entretanto, em outubro de 2005, o então presidente dos Estados Unidos, George W. Bush anunciou que a posição do país era favorável ao Protocolo de Kyoto para estabilizar os níveis de 1990. Porém, sem um compromisso de tratado assinado, perpetuou-se a duvidosa interação dessa nação com os reais objetivos do tratado e se alguns estados americanos, isoladamente, tomam providências em relação ao Protocolo (MARCOVITCH, 2006).

Estão excluídos da obrigatoriedade dessas metas, países em desenvolvimento como Brasil, Rússia, Índia, China e México, entre outros, devido ao processo tardio de sua industrialização. Porém, os países em desenvolvimento que estão no acordo possuem o objetivo de colaboração, procurando diminuir as emissões ou mitigá-las por meio de MDLs implantados e, assim, promoverem a realização do Comércio Internacional de Emissões, não havendo uma obrigatoriedade para tal (SEIFFERT, 2009).

A proposta de comercialização de Créditos de Carbono estabelece que, devido ao equilíbrio climático do planeta, não há fronteiras de atuação de onde se deve reduzir a emissão de GEEs. Exemplificando, se um país membro integrante do Protocolo de Kyoto tem metas de redução e ainda nada foi feitoe existem países em desenvolvimento que pertencem ao acordo, mas que não têm a obrigatoriedade de redução - e por sua vez tenha executado um projeto de redução de GEEs -,o mesmo é certificado pelo Comitê Executivo do MDL, atestado e conferido ao título de RCE; sendo que a redução de emissão gerada torna-se crédito ao país que a executou.

Como não há, ainda, uma meta definida para os países em desenvolvimento, todo investimento nesse plano poderá se convertido para uma negociação e proporcionar um comércio desse crédito, a ser ofertado a países compromissados com o acordo de redução, mas que não implantaram algum projeto MDL ou estão em um processo demorado ou conturbado de redução das emissões.

Conforme Ribeiro (2005), os participantes podem negociar as emissões de forma que poderá existir um mercado para tal. As medições são feitas no início do ano e, ao final, verifica-se as emissões reais. A empresa que se comprometer a participar deverá ceder ao Governo certa quantidade de permissões, proporcionais ao volume de emissões realizadas no período, o que implica no desempenho individual, podendo a entidade ter que efetuar complementos ou ser restituída no caso de sobras.

Nesse cenário, as nações pertencentes ao acordo, preocupam-se em alcançar suas metas de redução da emissão de gases poluentes, atuando assim sobre organizações e indústrias, impondo regras e legislações pertinentes ao controle de emissão de GEEs. Trata- 
se de uma cooperação entre países membros na equalização dos níveis mundiais, da qual ocorrerá um equilíbrio entre os países membros e a promoção da geração de investimentos nos seguintes setores econômicos: reforma nos setores de energia e transportes; promoção do uso de fontes energéticas renováveis; eliminação de mecanismos financeiros e de mercado inapropriados aos fins do Protocolo de Kyoto; limitação de emissões de metano no gerenciamento de resíduos e dos sistemas energéticos proteção deflorestas e de outros sumidouros de carbono.

Conforme Santos (2011), da Agência Ambiente Energia, o número de projetos de MDL, registrados no Conselho Executivo das Organizações das Nações Unidas (ONU), chegou à marca de 2.029, com a geração anual de 342 milhões em Créditos de Carbono, segundo dados do UneRiso Centre, de $1^{\circ}$ de fevereiro de 2010. A China (732), Índia (481), Brasil (168) e México (120) ocupam as quatro primeiras posições de países em desenvolvimento que realizam projetos. O Brasil tem $8,3 \%$ dos projetos registrados, sendo $5,9 \%$ de RCEs.

Estes quatro países respondem por $74 \%$ dos projetos de MDL, gerando cerca de 273 milhões de RCEs por ano. O país asiático tem 59\% das RCEs. O levantamento mostra que entre validação, processo de registro ou registrados o número de projetos atinge 3.726. A China tem 1.961; a Índia, 1.251; o Brasil, 350 e o México, 164.

Para o Ministério da Ciência e Tecnologia (MCT, 2011), das atividades de projeto em estágio de validação, aprovação e registro apresentados em sua última compilação, de 28 de fevereiro de 2011, um total de 7.202 projetos se encontravam em alguma fase do ciclo de projetos do MDL. Sendo 2.874 já registrados pelo conselho executivo do MDL e 4.328 em outras fases do ciclo. Neste posicionamento, o Brasil ocupa o terceiro lugar, com 479 projetos (7\%), a China ocupa primeiro lugar, com 2.782 (39\%) dos projetos, e a Índia, em segundo, com 1979 (27\%) dos projetos.

A visão econômica é oportunizada por Oliveira (2004) que utiliza em um diagrama baseado na Teoria de Sistemas. A economia da poluição demandaria três tipos de atuação. No paradigma coasiano haveria a atribuição do direito de poluir acordado entre os agentes.

Numa espécie de negociação privada, a poluição possibilitaria negociação entre, por exemplo, uma indústria química e uma pesqueira, de modo a atingir o nível ótimo de poluição. Essa alternativa é a que mais se ajusta à opção do Crédito de Carbono, muito embora as opções de tratamento da poluição como bem público, da regulamentação, da tributação pigouviana e das permissões negociáveis sejam opções também aplicáveis.

Na visão de Oliveira (2004), uma síntese é possível, considerando a necessidade de incorporar no sistema econômico mecanismos para a gestão socioambiental da poluição. $\mathrm{O}$ Crédito de Carbono representa uma evolução considerável, sendo alternativa viável e que sinaliza a liderança do Brasil como um dos maiores países com projetos potenciais.

A partir da visão sistêmica, pode-se estabelecer uma estilização do Crédito de Carbono no contexto econômico. Para estabelecer a função de produção são necessários insumos que são retirados da natureza. Como resultado do processo produtivo, existe a geração de resíduos devolvidos para a natureza. As famílias têm, por meio da produção, acesso ao trabalho, tido como fator de produção em busca do resultado final (output) do consumo.

O fluxo de geração de resíduos é que possibilita o desenvolvimento do Crédito de Carbono, pois a poluição é uma externalidade que não é considerada no modelo econômico tradicional. Uma vez caracterizada a poluição como externalidade, a racionalidade de capital, numa perspectiva de ecodesenvolvimento, passa a capturar o "custo poluição", por 
assim dizer, em benefício não apenas das famílias, prejudicadas por essa falha do modelo tradicional, mas, ainda, para a natureza que passa a ter suas possibilidades de perpetuidade aumentadas. Assim, o modelo de Desenvolvimento Sustentável, considerando a incorporação do MDL é mais completo, podendo ser estilizado como evidenciado na Figura 1 , a seguir.

Podem-se defender, com auxílio da Figura 1, que o Crédito de Carbono e o MDL são mecanismos que uma vez incorporados ao sistema de mercado pode propiciar benefícios de sustentabilidade. Ao utilizar com intensidade os mecanismos resíduos gerados por famílias e atividade econômica são reduzidos no que se refere ao descarte na natureza, destacando-se o processo de reciclagem.

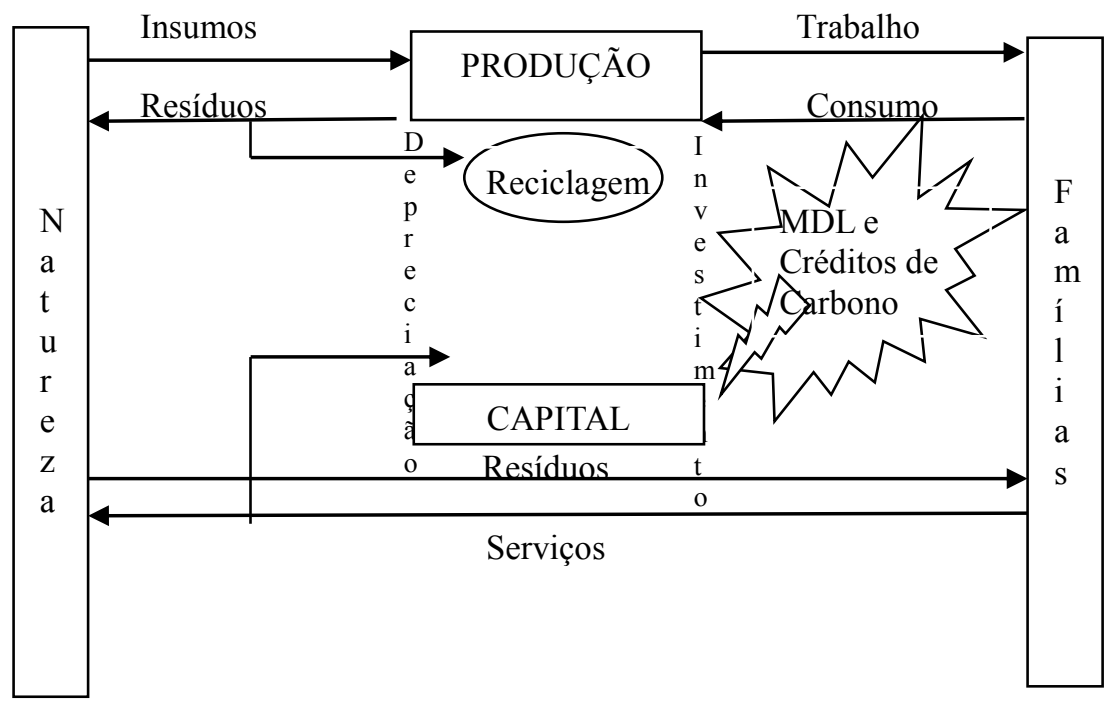

Figura 1: Incorporando o Crédito de Carbono e o MDL no Sistema Econômico Fonte: Adaptada de Oliveira (2004)

Focalizando no investimento do capital, ambientes sustentáveis podem demandar ações de agentes financeiros em oferecer taxas de juros reduzidas que podem ser estimuladas pelo mercado de crédito que terá mitigado riscos ambientais de empresas e famílias.

Ativos com atributo sustentável ensejam menor taxa de depreciação de investimentos protegidos de riscos de poluição, condições sanitárias e desagregação social. Sob o aspecto social o trabalho pode ser estimulado em novos setores e o consumo sustentável pode redundar em novos mercados consumidores e cadeias produtivas e distribuição baseadas em inovação. Dessa forma, pode-se perceber que o MDL e os Créditos de Carbono são mecanismos com implicações sustentáveis nos vetores econômico, social e ambiental.

Apesar de majoritariamente aceito, o MDL é objeto de algumas críticas, quiçá, céticas ao extremo. Contra essas visões, pode-se perceber que, frequentemente, surgem iniciativas de tributação mais favorecida, consumo responsável e responsabilização socioambiental que exemplificam a visão de que a sustentabilidade parece possuir- raízes profundas na sociedade contemporânea (BARBIERI, 2007). Nessa perspectiva, é provável que o MDL e a utilização de Crédito de Carbono, realidade incipiente para grandes empresas, possam se tornar aspecto central nos estudos de viabilidade técnica-econômica das empresas em geral, favorecendo o desenvolvimento de países e organizações. 


\section{PERCURSOS METODOLÓGICOS}

Este estudo pode ser considerado empírico-analítico, no que diz respeito à sua abordagem metodológica. No que tange aos procedimentos técnicos empregados, pode-se caracterizar esta como pesquisa bibliográfica, documental, bibliométrica e sociométrica. $\mathrm{Na}$ visão de Gil (2008,p.71), a pesquisa bibliográfica" é desenvolvida a partir de material já elaborado, constituído, principalmente, de livros e artigos científicos" e uma pesquisa documental, por sua vez, "vale-se de materiais que não recebera, ainda um tratamento analítico, ou que ainda podem ser reelaborados de acordo com os objetivos da pesquisa".

Os dados foram coletados por meio de pesquisa documental que, na perspectiva de Beuren (2004), é considerada fonte primária, já que seu conteúdo fornece embasamento para outras pesquisas. A segregação inicial foi realizada com a aplicação do software Copernic Desktop Search (2011), empregado para busca em bases de dados eletrônicas dos anais dos eventos pesquisados.

Especificamente, na pesquisa documental, foram analisados os artigos publicados nos seguintes eventos: Encontro Nacional dos Cursos de Pós-Graduação e Pesquisa em Administração (EnANPAD); Encontro Internacional sobre Gestão Ambiental e Meio Ambiente (ENGEMA); Seminários de Administração (SEMEAD/USP) e Sociedade Brasileira de Economia, Sociologia e Administração Rural (SOBER). Estes eventos foram selecionados por representarem as vitrines das produções acadêmicas em gestão socioambiental.

Em termos de produção em periódicos, foram analisados os seguintes: Revista de Administração Contemporânea (RAC); Revista de Administração de Empresas (RAE); RAE Eletrônica; Revista de Educação e Pesquisa em Contabilidade (REPEC); Revista de Administração (READ) e Revista de Administração da Universidade de São Paulo (RAUSP), selecionados a partir do ranking da Qualis da CAPES com posições A e B (de acordo com a antiga classificação) entre 2006 e 2012. Complementa a metodologia, a análise de periódicos disponíveis no Scielo por tratar-se de repositório de periódicos nacional de alto impacto na comunidade acadêmica.

A coleta nos periódicos foi realizada mediante busca eletrônica nos respectivos sites dos periódicos. Foram coletados todos os artigos, em cujo campo "palavras-chave" constava "Crédito de Carbono". Por serem palavras-chave correlatas, foram incluídas na pesquisa as seguintes palavras: "Mecanismo de Desenvolvimento Limpo" e "Protocolo de Quioto ou Kyoto".

Todas as análises desenvolvidas com base na produção científica, nas citações e nos conteúdos produzidos, fazem parte do objeto de estudo da bibliometria, caracterizando esta, também como uma pesquisa bibliométrica (ZHAO, 2006). Na visão de Macias-Chapula (1998, p. 134), a pesquisa bibliométrica está orientada para "o estudo dos aspectos quantitativos da produção, disseminação e uso da informação registrada".

A pesquisa bibliométrica envolve métodos empregados para estudar ou identificar textos e informação, que lidam com a relevância das propriedades dos documentos, sendo usados nas ciências da informação, utilizando análises quantitativas e estatísticas para descrever padrões de publicação dado um campo ou corpo de uma literatura (JALAL et al., 2009).

Moretti e Campanario (2009) realizaram um estudo bibliométrico no tema de responsabilidade social empresarial, reforçando que "para o entendimento da produtividade e do avanço do conhecimento é muito útil verificar quais são os autores e centros de pesquisa mais produtivos e que mais contribuem para o desenvolvimento de um campo de estudo" 
(MORETTI; CAMPANARIO, 2009, p. 72).

$\mathrm{Na}$ presente investigação bibliométrica, foram observados o ano de publicação, o número de autores dos artigos, as instituições às quais esses estão vinculados, as abordagens e os métodos utilizados nos artigos. Posteriormente, os artigos tiveram seus conteúdos analisados, seus objetivos, metodologias e conclusões organizadas, para que fossem averiguadas informações de autoria, vínculo e predominância epistemológica.

Adicionalmente, objetivando a identificação da vinculação entre pesquisadores e instituições, foi realizada uma análise sociométrica. Uma vez que se trata de assunto de caráter recente, é interessante avaliar se há concentração das pesquisas da área junto às instituições brasileiras, bem como quais são os pesquisadores mais produtivos em relação ao tema e se atuam de forma isolada ou conjunta com outras instituições de pesquisa.

A análise sociométrica ou de redes sociais de relacionamento está direcionada à exploração da matriz de relacionamentos estabelecida entre atores sociais (GALASKIEWICZ; WASSERMAN, 1994). No que diz respeito à análise das redes sociais, optou-se pela exploração das redes de coautoria entre autores, representativas de uma vertente de análise de redes sociais (WASSERMAN et al., 1994), por meio do software UCINET® 6, de acordo com as áreas de publicação.

Uma utilização relevante da análise de redes sociais é a identificação dos autores mais importantes da rede (WASSERMAN; FAUST, 1994). A definição de importância indica que um autor tem destaque por apresentar um número grande de laços (ligações) com outros autores devido à quantidade de trabalhos publicados em conjunto. Neste caso, o laço representa a coautoria dos trabalhos publicados. Portanto, na sequência, serão apresentadas a análise e discussão dos resultados.

\section{ANÁLISE E DISCUSSÃO DOS RESULTADOS}

Na pesquisa desenvolvida, foram encontrados 74 artigos sobre o tema Crédito de Carbono, no período de 2006 a 2012:

Tabela 1: Total de Artigos Publicadosno Brasil por ano

\begin{tabular}{c|c|c}
\hline Ano & Quantidade & Participação (\%) \\
\hline 2006 & 6 & $8,1 \%$ \\
2007 & 16 & $21,6 \%$ \\
2008 & 8 & $10,8 \%$ \\
2009 & 4 & $5,4 \%$ \\
2010 & 15 & $20,3 \%$ \\
2011 & 22 & $29,7 \%$ \\
2012 & 3 & $4,1 \%$ \\
\hline Total & 74 & $\mathbf{1 0 0 , 0} \%$ \\
\hline \multicolumn{2}{c}{ Fonte: Dados da Pesquisa (2012). }
\end{tabular}

Em relação a uma análise longitudinal, verifica-se que o tema Créditos de Carbono não apresentou uma tendência de crescimento, porém apresentou oscilações entre os anos. Os anos de 2007, 2010 e 2011 apresentaram maior concentração de trabalhos sobre o referido tema. 
Tabela 2: Total de Artigos Publicados em Eventos no Brasil por ano

\begin{tabular}{|c|c|c|c|c|c|c|c|c|c|c|}
\hline EVENTO & 2006 & 2007 & 2008 & 2009 & 2010 & 2011 & 2012 & TOTAL & $\begin{array}{c}\text { TOTAL } \\
\%\end{array}$ & $\begin{array}{c}\text { EVENTOS } \\
\%\end{array}$ \\
\hline BIREME/COPPE/UFRJ & & 1 & & & & & & 1 & $1,4 \%$ & $1,8 \%$ \\
\hline ENANGRAD & & 2 & & & & & & 2 & $2,7 \%$ & $3,6 \%$ \\
\hline ENANPAD & 4 & 2 & 2 & 1 & 6 & 3 & 2 & 20 & $27,0 \%$ & $35,7 \%$ \\
\hline ENGEMA & & 5 & & & & 9 & & 14 & $18,9 \%$ & $25,0 \%$ \\
\hline SEMEAD & 2 & & & 1 & 2 & 3 & & 8 & $10,8 \%$ & $14,3 \%$ \\
\hline SOBER & & 2 & 4 & & & & & 6 & $8,1 \%$ & $10,7 \%$ \\
\hline USP DE CONTR./CONT. & & & & & 1 & 4 & & 5 & $6,8 \%$ & $8,9 \%$ \\
\hline Total & 6 & 12 & 6 & 2 & 9 & 19 & 2 & 56 & $75,7 \%$ & \\
\hline$\%$ Ano & $10,7 \%$ & $21,4 \%$ & $10,7 \%$ & $3,6 \%$ & $16,1 \%$ & $33,9 \%$ & $3,6 \%$ & $100,0 \%$ & & \\
\hline
\end{tabular}

Fonte: Dados da Pesquisa (2012).

A análise longitudinal permite verificar que os veículos não são homogêneos em relação à publicação continuada dos temas. Salvo publicações isoladas, no período de 2006 a 2012, poucos veículos evidenciam uma continuidade de publicações no tema. Apenas o evento EnANPAD apresentou publicação em todos os anos. Nesse contexto, os eventos ENANPAD (27,0\%), ENGEMA (18,9\%), SEMEAD (10,8\%) e SOBER $(8,1 \%)$ representam os eventos majoritários em ocorrência de publicação em Créditos de Carbono.

Analisada apenas a publicação de eventos, pode-se perceber que houve crescimento nas publicações de crédito de carbono, totalizando 56 artigos, a saber: 20 no EnANPAD $(35,7 \%) ; 6$ (seis) no SOBER (10,7\%);8 (oito) no SEMEAD (14,3\%);14 no ENGEMA (25,0\%) e 5 (cinco) no Congresso USP de Controladoria e Contabilidade. Verifica-se uma dominância do EnANPAD na publicação da área.

Em complemento, são ainda poucos os periódicos brasileiros, ranqueados pela Qualis/Capes, que aceitaram publicações sobre o tema Créditos de Carbono, conforme se pode observar na Tabela 2. Destacam-se a RGSA e a REAd com participações de 5,4\% e 2,7\%, respectivamente. Cabe destacar que o periódico RGSA, específico sobre o tema socioambiental, também apresentou constância de publicação sobre o tema pesquisado. Os demais apresentaram um padrão homogêneo, apresentandouma publicação. Dos 74 artigos publicados, verificou-se menor predominância de publicação em periódicos, com apenas 18, conforme pode ser observado na Tabela 3:

Tabela 3: Total de Artigos Publicados em Periódicos no Brasil por ano

\begin{tabular}{|c|c|c|c|c|c|c|c|c|c|c|}
\hline PERIÓDICO & 2006 & 2007 & 2008 & 2009 & 2010 & 2011 & 2012 & TOTAL & \begin{tabular}{|c|} 
TOTAL \\
$\%$ \\
\end{tabular} & $\begin{array}{c}\text { REVISTAS } \\
\% \\
\end{array}$ \\
\hline RAUSP & & 1 & & & & & & 1 & $1,4 \%$ & $5,6 \%$ \\
\hline READ & & & & 1 & 1 & & & 2 & $2,7 \%$ & $11,1 \%$ \\
\hline Revista Adm. Empresas & & & & & 1 & & & 1 & $1,4 \%$ & $5,6 \%$ \\
\hline RGSA & & & 1 & 1 & 2 & & & 4 & $5,4 \%$ & $22,2 \%$ \\
\hline Scielo/ Eng. Agríc. & & 1 & & & & & & 1 & $1,4 \%$ & $5,6 \%$ \\
\hline Scielo/ Gestão \& Produção & & & & & 1 & & & 1 & $1,4 \%$ & $5,6 \%$ \\
\hline Scielo/Interações & & 1 & & & & & & 1 & $1,4 \%$ & $5,6 \%$ \\
\hline Scielo/ Revista Árvore & & & & & & 1 & & 1 & $1,4 \%$ & $5,6 \%$ \\
\hline Scielo/Contexto Int. & & & 1 & & & & & 1 & $1,4 \%$ & $5,6 \%$ \\
\hline Scielo/Econ. Aplicada & & 1 & & & & & & 1 & $1,4 \%$ & $5,6 \%$ \\
\hline Scielo/Eng. Sanit. Ambient. & & & & & & & 1 & 1 & $1,4 \%$ & $5,6 \%$ \\
\hline
\end{tabular}




\begin{tabular}{|c|c|c|c|c|c|c|c|c|c|c|}
\hline Scielo/Pesquisa Operacional & & & & & & 1 & & 1 & $1,4 \%$ & $5,6 \%$ \\
\hline Scielo/Sobrapo & & & & & 1 & & & 1 & $1,4 \%$ & $5,6 \%$ \\
\hline Scielo/Rev.Fac.Cienc.Econ. & & & & & & 1 & & 1 & $1,4 \%$ & $5,6 \%$ \\
\hline Total & 0 & 4 & 2 & 2 & 6 & 3 & 1 & 18 & $24,3 \%$ & $100,0 \%$ \\
\hline$\%$ Ano & $0,0 \%$ & $22,2 \%$ & $11,1 \%$ & $11,1 \%$ & $33,3 \%$ & $16,7 \%$ & $5,6 \%$ & $100,0 \%$ & & \\
\hline
\end{tabular}

Fonte: Dados da Pesquisa (2012)

Não obstante a menor aceitação de artigos em periódicos nos primeiros anos, parece que a qualidade e quantidade da produção em Créditos de Carbono têm aumentado. Em relação aos períodos, destacam-se a Revista de Gestão Socioambiental (RGSA) e a Revista de Administração (READ). Outros periódicos com um artigo cada, são, por exemplo, RAUSP, RAE, ENG. AGRICOLA, GESTÃO e PRODUÇÃO, INTERAÇÕES, sendo possível identificar outros periódicos ranqueados no QUALIS-CAPES disponibilizados no portal SCIELO. No que diz respeito ao ranqueamento da Qualis/Capes-ADM, o resultado foi elaborado na Tabela 4:

Tabela 4: Classificação dos Artigos Publicados no Brasil

\begin{tabular}{crrrrrrrrrrr}
\hline QUALIS & A2 & B1 & B2 & B3 & B4 & C & E1 & E2 & NC & TOTAL \\
\hline TOTAL & 5 & 4 & 4 & 2 & 1 & 1 & 20 & 33 & 4 & 74 \\
\hline TOTAL $\%$ & $6,8 \%$ & $5,4 \%$ & $5,4 \%$ & $2,7 \%$ & $1,4 \%$ & $1,4 \%$ & $27,0 \%$ & $44,6 \%$ & $5,4 \%$ & $100,0 \%$ \\
\hline \multicolumn{1}{c}{ Fonte: Dados da Pesquisa $(2012)$} & &
\end{tabular}

A pequena inserção em periódicos (18 artigos), apesar de reduzida em relação à quantidade total de artigos (74), deu-se de forma equilibrada em periódicos de qualidade, segundo critérios adotados. Contudo, há uma distribuição pouco equilibrada entre os eventos de maior qualidade (E1) e os de menor (E2). Os últimos concentram a produção. Avançando um pouco mais a análise sobre autores e instituições de vínculo, verifica-se a liderança de duas instituições de pesquisadores: a Universidade Federal da Bahia e da Universidade de São Paulo. Essas são seguidas por outras duas: Universidade Federal do Rio de Janeiro e Universidade de São Caetano do Sul.

Tabela 5: Artigos Publicados por Autor no Brasil

\begin{tabular}{l|c|c}
\hline \multicolumn{1}{c|}{ Autores mais produtivos } & Vínculo Institucional & $\begin{array}{c}\text { Quantidade de } \\
\text { autorias / coautorias }\end{array}$ \\
\hline Antônio Costa Silva Júnior & UFBA & 5 \\
Luana das Graças Queirós de Farias & UFBA & 4 \\
Maísa de Souza Ribeiro & USP & 4 \\
José Célio Silveira Andrade & UFBA & 4 \\
Amaury José Resende & USP & 3 \\
Andrea Cardoso Ventura & UFBA & 3 \\
Celso Funcia Lemme & UFRJ & 3 \\
Flávia Zóboli Dalmácio & USP & 3 \\
Raquel da Silva Pereira & USCS & 3 \\
Kristian Brito Pasini & UFBA & 3 \\
Autores com 2 publicações & Diversas instituições & 18 \\
Autores com 1 publicação & Diversas instituições & 156 \\
\hline Total de autorias & & $\mathbf{2 0 9}$ \\
\hline
\end{tabular}

Fonte: Dados da pesquisa (2012) 
Destacam-se aspectos de autoria. Há artigos que possuem 1, 2, 3, 4 ou mais autores, ainda em que algumas autorias se repitam. O número de autorias e coautorias (209) supera a quantidade de artigos (74). Considerando-se os autores que mais publicaram sobre Créditos de Carbono no Brasil, verifica-se a liderança em um contexto de dispersão de autorias.

A Universidade Federal da Bahia (UFBA) possui os autores Antônio Costa Silva Júnior com maior número de publicações 5 (cinco) artigos, Luana das Graças Queirós Farias e José Célio Silveira Andrade seguem a lista com 4 (quatro) artigos. Segue a Universidade de São Paulo (USP) que possui autora com 4 (quatro) publicações: Maísa de Souza Ribeiro. Outros autores são destacáveis da Universidade de São Paulo, Universidade Federal do Rio de Janeiro, Universidade Federal do Rio de Janeiro e Universidade Municipal de São Caetano do Sul com 3 (três) publicações.

Chama a atenção o fato de que não há uma concentração de pesquisadores e universidades, no que se refere ao tema Crédito de Carbono. É possível que se trate de potencial pulverização e de interesse de público diverso de pesquisadores. Outra análise desenvolvida está relacionada à predominância epistemológica dos artigos selecionados.

Tabela 6: Predominância Epistemológica

\begin{tabular}{lrr}
\hline \multicolumn{1}{c}{ PERFIL EPISTEMOLÓGICO } & Total & \multicolumn{1}{c}{$\%$} \\
\hline Empírico & 16 & $21,6 \%$ \\
Estudo Teórico & 7 & $9,5 \%$ \\
Qualitativo & 12 & $16,2 \%$ \\
Qualitativo e Quantitativo & 17 & $23,0 \%$ \\
Quantitativo & 22 & $29,7 \%$ \\
\hline Total Geral & 74 & $100,0 \%$ \\
\hline \multicolumn{3}{c}{ Fonte: Dados da pesquisa (2012) }
\end{tabular}

Verifica-se, no total de 74 artigos, uma baixa ênfase teórica. Cabe analisar detalhadamente essa ocorrência nos eventos e periódicos na Tabela 7:

Tabela 7: Total de Artigos Publicados no Brasil por tipo de publicação

\begin{tabular}{|c|c|c|c|c|c|c|c|}
\hline EVENTO/PERIÓDICO & EMPÍRICO & TEÓRICO & QUALI & $\begin{array}{l}\text { QUALI E } \\
\text { QUANTI }\end{array}$ & QUANTI & TOTAL & $\%$ \\
\hline BIREME/COPPE/UFRJ & & 1 & & & & 1 & $1,4 \%$ \\
\hline CONG USP DE & & & & & & & \\
\hline CONTR/CONT & & 1 & & 3 & 1 & 5 & $6,8 \%$ \\
\hline ENANGRAD & & & & & 2 & 2 & $2,7 \%$ \\
\hline ENANPAD & 5 & 2 & 2 & 6 & 5 & 20 & $27,0 \%$ \\
\hline ENGEMA & 4 & 3 & 3 & 4 & & 14 & $18,9 \%$ \\
\hline RAUSP & & & 1 & & & 1 & $1,4 \%$ \\
\hline READ & 2 & & & & & 2 & $2,7 \%$ \\
\hline REVISTA DE ADM. DE & & & & & & & \\
\hline EMPRESAS & & & 1 & & & 1 & $1,4 \%$ \\
\hline RGSA & 4 & & & & & 4 & $5,4 \%$ \\
\hline SCIELO/ ENG. AGRÍC. & & & & & 1 & 1 & $1,4 \%$ \\
\hline SCIELO/ GESTÃO E & & & & & & & \\
\hline PRODUÇÃO & & & & & 1 & 1 & $1,4 \%$ \\
\hline SCIELO/ INTERAÇÕES & & & & & 1 & 1 & $1,4 \%$ \\
\hline Scielo/ Revista Árvore & & & & 1 & & 1 & $1,4 \%$ \\
\hline
\end{tabular}




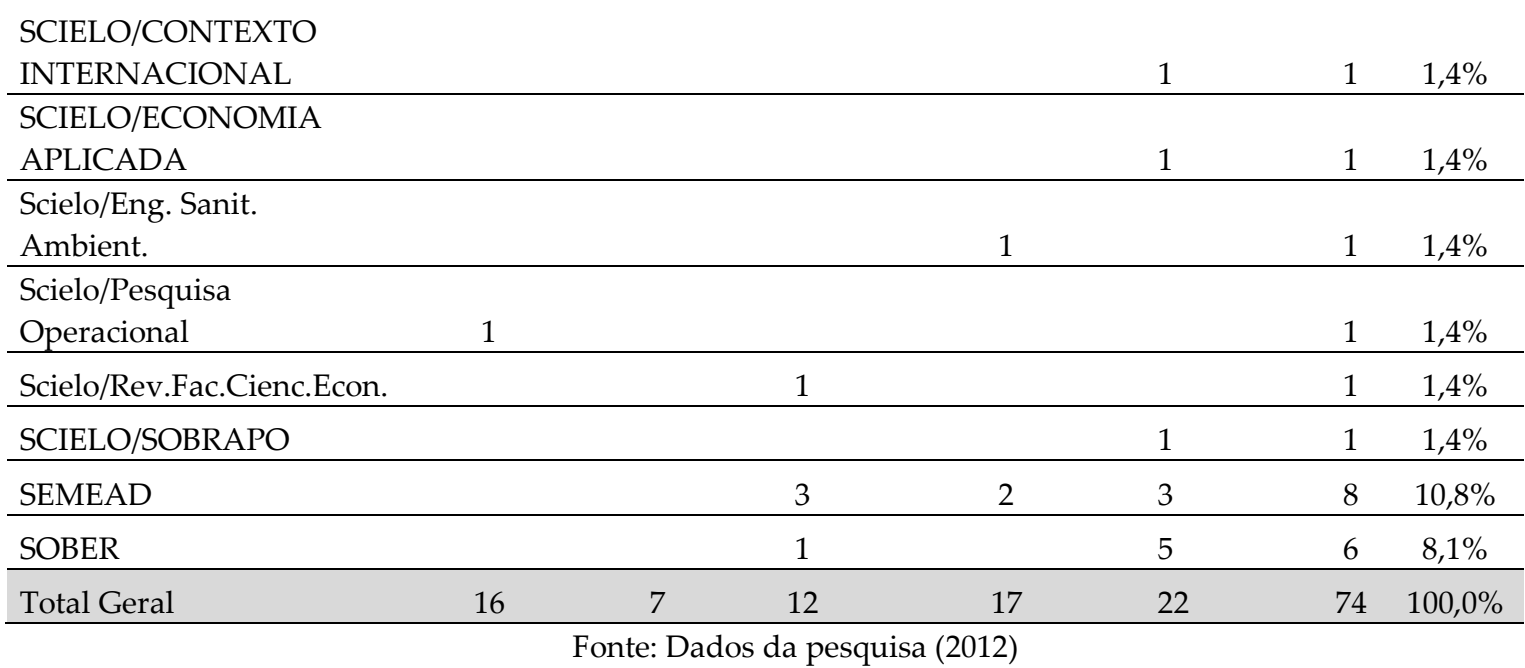

Constatou-se uma situação de heterogeneidade de epistemologia entre os periódicos e eventos. Enquanto o EnANPAD mostra-se mais equilibrado,o periódico RGSA é concentrado em estudos empíricos e o evento SOBER prioriza estudos quantitativos. Para os demais veículos, o que se verifica é uma baixa taxa de publicação. Tal situação dificulta avaliar até que ponto é consistente descrever que exista uma predominância epistemológica por veículo.

Em termos de perfil epistemológico, há uma diferenciação entre os periódicos e eventos. Há aquelas em que o atributo empírico ocorreu no EnANPAD e nos periódicos READ e RGSA. Estudos qualitativos foram detectados nos eventos EnANPAD, SEMEAD e SOBER, sendo que, ainda, apareceram nos periódicos RAUSP, ERA e REPEC. Quando se buscam estudos qualitativos e quantitativos, esses são localizados apenas nos eventos: EnANPAD, ENGEMA, Congresso USP de Controladoria e no SEMEAD.

Estudos quantitativos possuem mais adesão geral dos eventos e periódicos, sendo detectados nos encontros da ENANGRAD, EnANPAD, SEMEAD e SOBER. Estudos quantitativos foram aceitos nos periódicos do repositório do SCIELO: ENG.ENHARIA AGRÍCOLA, GESTÃO E PRODUÇÃO, INTERAÇÕES, CONTEXTO INTERNACIONAL, ECONOMIA APLICADA e Revista da SOBRAPO.

Knoke e Yang (2008) trazem abordagens importantes para a presente investigação, na qual os autores dos artigos são os atores e as relações são os vínculos de co-autoria. Na visão desses autores, podem ser pessoas individuais ou coletivas, tais como grupos informais ou organizações formais, atuando em rede. Dentre os exemplos mais comuns de atores individuais, estão os organizados em equipes empresariais ou indústrias que competem em um setor.

Este trabalho utiliza o conceito de ego-centered network, que consiste de um determinado ego (autor), dos autores ligados a ele e dos laços entre esses autores (NEWMAN, 2010). Cabe ressaltar, conforme foi destacado por Arruda et al. (2013, p. 187) que, "um grande número de laços entre vários autores pode representar apenas um trabalho feito em conjunto; e um autor com laços estabelecidos com vários outros, os quais não apresentam ligações entre si, indica que aquele autor é prolífico, por indicar vários trabalhos realizados". A análise sociométrica, realizada por meio do software UCINET® 6, identifica as redes de parcerias existentes, apresentadas na Figura 2: 


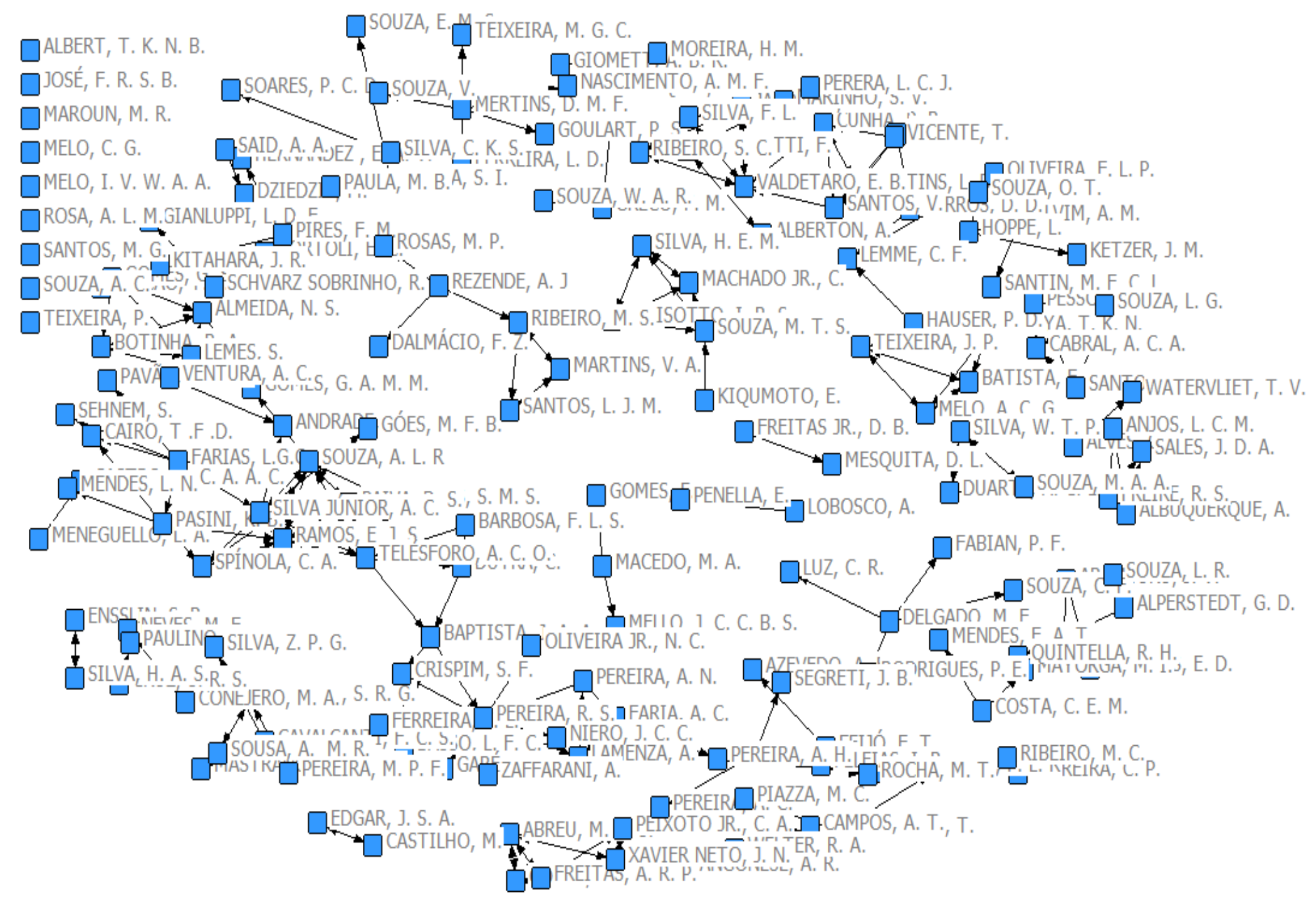

Figura 2: Rede Social de Pesquisadores de Créditos de Carbono. Fonte: Dados da Pesquisa (2012). 
A análise sociométrica mostra uma primeira situação, na qual há pesquisadores que atuam isoladamente e outros em conjunto. Foram detectados 9 (nove) autores que publicaram individualmente sobre o tema de Créditos de Carbono e MDL. A produção individual não é a prática majoritária, pois foi verificado um padrão de estabelecimento de laços entre autores para viabilizar suas produções científicas.

É possível identificar na Figura 3, a seguir, que há uma heterogeneidade das redes de pesquisadores. Não bastassem alguns pesquisadores, que atuam isoladamente, não foi possível caracterizar uma rede brasileira integrada de pesquisa, sendo possível detectar um padrão de pesquisas realizadas isoladamente por pesquisadores de algumas universidades que atuam isoladamente.
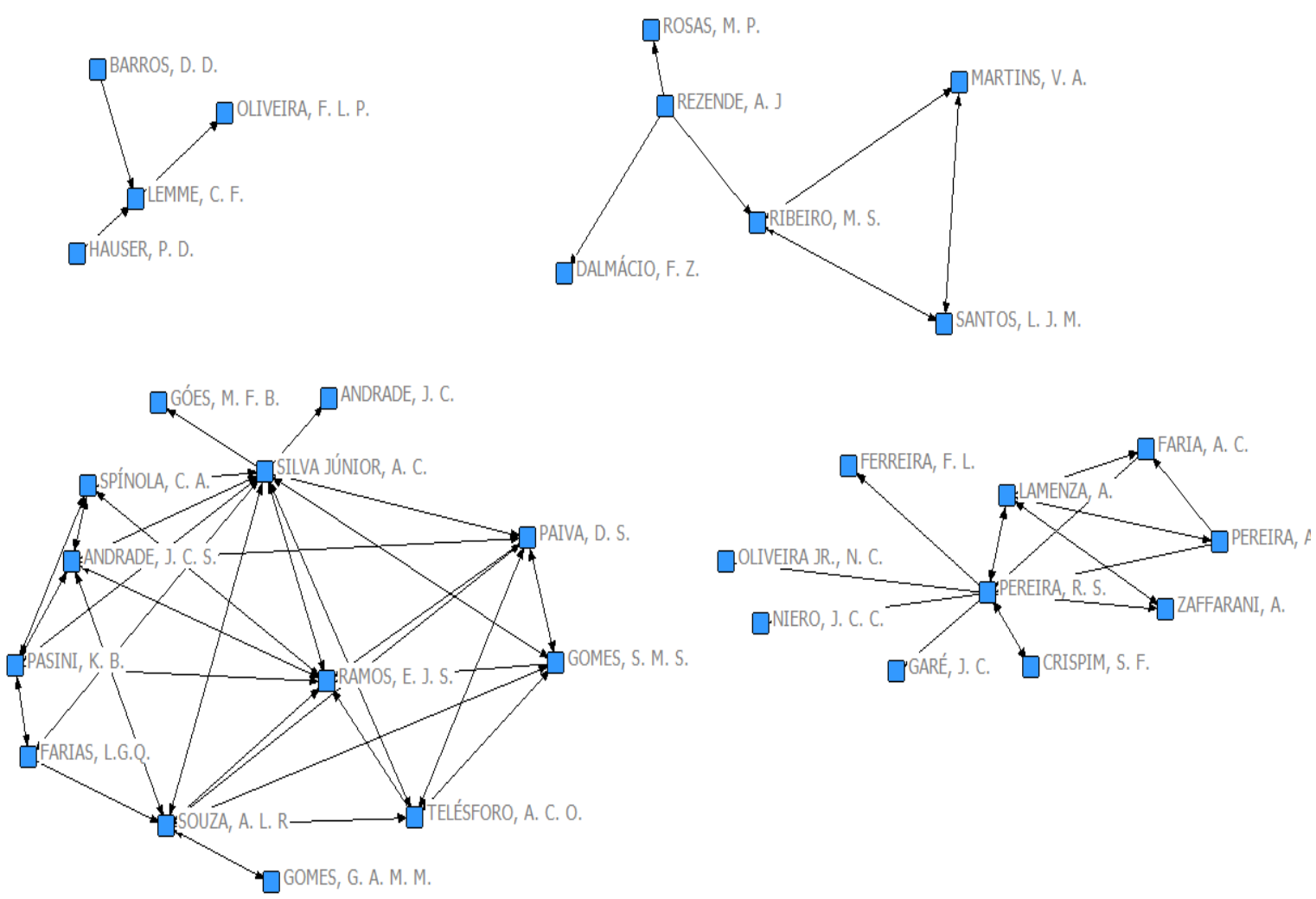

Figura 3: Rede de Pesquisadores mais produtivos em Créditos de Carbono. Fonte: Dados da Pesquisa (2012).

Para a análise dos vínculos entre pesquisadores, 4 (quatro) pesquisadores aparecem como centrais nas referidas redes. Farias (UFBA), Lemme (UFRJ), RIBEIRO (USP-FEARP) e PEREIRA (USCS) são os autores que apresentaram maior quantidade de artigos publicados e exibem grande quantidade de vínculos. Uma rede, em especial, a da Universidade Federal da Bahia possui maior densidade de vínculos e número de pesquisadores, sinalizando maior constância e maior institucionalização da produção científica na área de crédito de carbono.

Após a análise das redes de pesquisadores, percebe-se ausência de laços entre pesquisadores de instituições diferentes. Nesse aspecto detectou-se, a partir da bibliometria, um fenômeno já bem documentado e discutido pelos teóricos de redes.

Reportando-se ao conceito de buraco estrutural, definido como a ausência de conexões entre grupos (JACKSON, 2008, p-70-71), uma orientação consensual na literatura de redes é que o preenchimento dos "laços ausentes" entre os grupos poderia, por exemplo, promover um maior dinamismo no fluxo de informações em benefício dos grupos no que se refere à produtividade e sinergia científica. 
Numa perspectiva propositiva, a partir da literatura de rede, a existência de autores conectores poderia favorecer a difusão da pesquisa em Créditos de Carbono, aparentemente, produzida de forma isolada e atomicista. Nessa perspectiva, vislumbra-se que seriam desejáveis benefícios de coautoria em benefício da qualidade da produção científica na área.

\section{CONSIDERAÇÕES FINAIS}

Nesta pesquisa propôs-se a mapear a produção acadêmica brasileira sobre o tema Créditos de Carbono; mais especificamente os artigos publicados em periódicos e eventos científicos até 2012. Este objetivo foi atingido com base na análise bibliométrica e de redes sociais, em que é relevante caracterizar, preliminarmente, os conceitos de atores e relações, difundidos por Knoke e Yang (2008).

Após o desenvolvimento da pesquisa foi possível identificar que a produção científica sobre Crédito de Carbono está concentrada em eventos. Os eventos EnANPAD, SOBER, ENGEMA e SEMEAD representam os eventos majoritários em ocorrência de publicação em Crédito de Carbono. Em termos de periódicos, destacam-se a RGSA e a REAd como dedicados à publicação do temática investigada no presente artigo.

Em consonância aos procedimentos metodológicos desenvolvidos, a predominância epistemológica recaiu, de forma significativa, sobre o perfil quantitativo, seguido dos estudos empírico e o qualitativo/quantitativo. Pode-se perceber que ocorreu uma razoável diversidade epistemológica na amostra analisada.

No que tange às redes de pesquisadores, verificou-se que essas são formadas por estudiosos da Universidade Federal da Bahia, Universidade de São Paulo e Universidade Federal do Rio de Janeiro. As redes evidenciam características de endogenia e isolamento, não sendo evidenciados vínculos entre as três redes mais produtivas.

Por meio da bibliometria foi possível detectar uma possível disfunção bem discutida na literatura de redes sociais: os buracos estruturais. Como implicação da presente pesquisa, é possível que surjam benefícios relevantes caso sejam proporcionados laços entre os grupos de pesquisa. Tal fato poderia, por exemplo, não apenas acelerar e qualificar a produção científica brasileira em Créditos de Carbono, mas, ainda, fortalecer canais para a geração, publicação e aplicação de um conhecimento recente e de relevância para a produção nacional, pautada pela sustentabilidade.

Por fim, cabe registrar que a presente pesquisa possui limitações. Uma é decorrente da baixa ênfase nos vínculos de atores com menor quantidade de publicações. No entanto, reconhece-se a importância dessa unidade analítica, pois mesmo fora de estruturas de redes, pesquisas sobre Créditos de Carbono são identificáveis. Há, ainda outras frentes de pesquisa bibliométrica.

Com base na relevância do tema em questão, considera-se que este trabalho contribui, tanto para o meio acadêmico quanto para o empresarial, pois foi mapeada a rede dos pesquisadores brasileiros atuantes em análises sobre Créditos de Carbono até 2012, demonstrando, por assim dizer, os geradores de evidência e teoria mais relevantes para a referida área. Para futuras pesquisas sugere-se que esta pesquisa seja replicada para mapear a produção mundial sobre o tema, destacando os pesquisadores estrangeiros mais prolíficos.

Outra coisa que se tem em mente para pesquisas futuras, é que os pesquisadores aguardem regulamentação dos órgãos governamentais, que nortearão os critérios a serem adotados, por exemplo, frente à contabilização dos Créditos de Carbono e evidenciação das informações sobre os mesmos em demonstrações contábeis e nos relatórios de 
sustentabilidade das empresas de diversos segmentos, a fim de verificar se as mesmas estarão alinhadas com os conceitos normativos governamentais.

\section{REFERÊNCIAS}

ARRUDA, A. G. S.; BENEVIDES, G.; FARINA, M. C.; FARIA, A. C. Teoria dos Custos de Transação (TCT): Análises Bibliométrica e Sociométrica nos EnANPADs de 1997 a 2010. Revista de Administração da UNIMEP, v.11, n.2, Maio/Agosto, 2013, p. 174-199.

BARBIERI, J. C. Organizações inovadoras sustentáveis. In: BARBIERI, J. C.; SIMANTOB, M. A (Org). Organizações inovadoras sustentáveis. São Paulo: Atlas, 2007.

BEUREN, I.M. Como Elaborar trabalhos monográficos em contabilidade. São Paulo: Atlas, 2004.

COPERNIC. Copernic Desktop Search. Disponível em: $<$ http://www.copernic.com/en/products/desktop-search/home/download.html>. Acesso em: 10 fev. 2011.

GALASKIEWICZ, J.; WASSERMAN, S. Advances in social network analysis. London: Sage, 1994.

GIL,A.C. Métodos e técnicas de pesquisa social. 6a. ed. São Paulo: Atlas, 2008.

IPCC. Intergovernmental Panel on Climate Change. Disponível: $<$ http://www.ipcc.ch/graphcs/gr-climate-changes-2001-syr.htm>. Acesso em: 8 dez. 2010.

JALAL,S M; BISWAS S. C; MUKHOPADHYAY P. Bibliometrics to webometrics Information Studies. v. 15, n. 1, 2009, p. 3-20.

JACKSON, M. O. Social and economic networks. Princeton: Princeton University Press, 2008.

KNOKE, D.; YANG, S. Social network analysis. 2a. ed. New York: Sage Publications, 2008. LELÉ, S. M. Sustainable Development: a critical review. World Development. v.19, n. 6, 1991, p. 607-621.

MACIAS-CHAPULA, C. A. O papel da infometria e da cienciometria e sua perspectiva nacional e internacional. Ciência da informação, v. 27, n. 2, 1998, p. 64-68.

MACIEL, C. M. V.; COELHO, A.R.G.; SANTOS, A.M.; LAGIOIA, U.C.T.; LIBONATI, J.J.; MACEDO, J.M.A. Crédito de carbono: Comercialização a partir de projetos de mecanismos de desenvolvimento limpo. Revista de Informação Contábil, v. 3, n. 1, 2009, p. 89-112.

MARCONDES, A. W.; LAVORATTO, M. L.; RUSCHEL, R. R. BenchMais. São Paulo: Envolverde, 2007. 
MARCOVITCH, J. Para mudar o futuro. São Paulo: Editora da Universidade de São Paulo / Saraiva 2006.

MILLER JR, G.. T. Ciência ambiental. São Paulo: Cengage Learning, 2008.

MORAES, O. J. Economia ambiental. São Paulo: Centauro, 2009.

MORETTI, S. L. A.; CAMPANARIO, M. A. A produção intelectual brasileira em responsabilidade social empresarial - RSA sob a ótica da bibliometria. Revista de Administração Contemporânea (RAC), v. 13, ed. especial, 2009.

OLIVEIRA, R. G. Economia do meio ambiente. In: PINHO, D. B.; VASCONCELLOS, M. A. S. Manual de economia. 5a. ed. São Paulo: Saraiva. 2004.

PEDROSO, S. A. Brasil é o $3^{o}$ em atividades de projeto de crédito de carbono. Diário do Grande ABC. 2008. Disponível em: <http://www.dgabc.com.br/News/30879/brasil-e-o-3-ematividades-de-projeto-de-crédito-de-carbono>. Acesso em 18 jan. 2011.

PEREIRA, R. S. Desenvolvimento sustentável com responsabilidade social das empresas. São Paulo: Lorosae, 2002.

PEREZ, R.A.; RIBEIRO, M.S.; CUNHA, J.V.A.; REZENDE, A. J. Reflexos contábeis e socioambientais dos Créditos de Carbono Brasileiros. REPEC - Revista de Educação e Pesquisa em Contabilidade. v. 2, n. 3, 2008, p. 56-83.

RIBEIRO, M. S. O tratamento contábil dos créditos de carbono. 2005. 90f. Tese (Livre Docência). Faculdade de Economia, Administração e Contabilidade de Ribeirão Preto, Universidade de São Paulo, Ribeirão Preto, 2005.

SACHS, I. Estratégias de transição para o Século XXI. São Paulo: Studio Nobel, 1993.

SANTOS, J. MDL Brasil responde por $8,3 \%$ dos projetos registrados. Disponível em: $<$ http://www.ambienteenergia.com.br/index.php/2010/06/mdl-brasil-responde-por-83-dosprojetos-registrados/3632>. Acesso em: 15 fev. 2011.

SEGRETI, J.B.; BITO, N.S. Crédito de Carbono. RBGN - Revista Brasileira de Gestão de Negócios. v. 8, n. 21, p.82-91, 2006.

SEIFFERT, M. E. B. Mercado de carbono e Protocolo de Quioto. São Paulo: Atlas, 2009.

WASSERMAN, S.; FAUST, K. Social network analysis. New York: Cambridge University Press, 1994.

YAMIN, F. Climate change and carbon markets. London: Earthscan, 2006.

ZHAO, L. How library used e-resources - an analysis of citation in CCQ. Cataloging and Classification Quarterly, v. 42, n. 1, 2006, p. 117-131. 